\title{
Optimization of the Degradation of Hydroquinone, Resorcinol and Catechol Using Response Surface Methodology
}

\author{
Noureddine Elboughdiri1,2*, Ammar Mahjoubi1,2, Ali Shawabkeh1, \\ Hussam Elddin Khasawneh' ${ }^{1}$, Bassem Jamoussi ${ }^{3}$ \\ ${ }^{1}$ Department of Chemical Engineering, College of Engineering, University of Hail, Hail, KSA \\ ${ }^{2}$ Department of Chemical Engineering Process, National School of Engineering of Gabes, Gabes, Tunisia \\ ${ }^{3}$ Department of Physical, High Institute of Education and Continuing Formation, Bardo, Tunisia \\ Email: "ghilaninouri@yahoo.fr
}

Received 12 February 2015; accepted 28 February 2015; published 4 March 2015

Copyright (C) 2015 by authors and Scientific Research Publishing Inc.

This work is licensed under the Creative Commons Attribution International License (CC BY).

http://creativecommons.org/licenses/by/4.0/

(c) (i) Open Access

\section{Abstract}

A clay catalyst (montmorillonite and kaolinite) was prepared and used to degrade three phenolic compounds: hydroquinone, resorcinol and catechol obtained from the treatment the Olive Mill Wastewater (OMW) generated in the production of olive oil. The operating conditions of the degradation of these compounds are optimized by the response surface methodology (RSM) which is an experimental design used in process optimization studies. The results obtained by the catalytic tests and analyses performed by different techniques showed that the modified montmorillonites have very interesting catalytic, structural and textural properties; they are more effective for the catalytic phenolic compound degradation, they present the highest specific surface and they may support iron ions. We also determined the optimal degradation conditions by tracing the response surfaces of each compound; for example, for the catechol, the optimal conditions of degradation at pH 4 are obtained after $120 \mathrm{~min}$ at a concentration of $\mathrm{H}_{2} \mathrm{O}_{2}$ equal to $0.3 \mathrm{M}$. Of the three phenolic compounds, the kinetic degradation study revealed that the hydroquinone is the most degraded compound in the least amount of time. Finally, the rate of the catalyst iron ions release in the reaction is lower when the Fe-modified montmorillonites are used.

\section{Keywords}

Fenton Process, Fe-Modified Clay, Phenolic Compounds, Response Surface Methodology

\footnotetext{
${ }^{*}$ Corresponding author.
}

How to cite this paper: Elboughdiri, N., Mahjoubi, A., Shawabkeh, A., Khasawneh, H.E. and Jamoussi, B. (2015) Optimization of the Degradation of Hydroquinone, Resorcinol and Catechol Using Response Surface Methodology. Advances in Chemical Engineering and Science, 5, 111-120. http://dx.doi.org/10.4236/aces.2015.52012 


\section{Introduction}

All over the world, domestic and industrial discharges and agricultural pollution have greatly contributed to deteriorating surface and groundwater quality. These pollutants have an important impact on the environment and human health. Significant efforts have been made to reduce pollutant discharges by promoting clean technologies in industrial sectors and by cleaning up waste gas and waste water before discharging them into the environment [1].

The latest advances in water treatment have been achieved in the oxidation of organic compounds [2] [3] including phenolic compounds which are harmful to the environment and to human health [4] [5].

For example, the Advanced Oxidation Process (AOP) is based on the in situ formation of highly reactive chemical entities such as hydroxyl radicals $(\mathrm{OH} \cdot)$. These radicals possess a high power of oxidation of organic molecules to $\mathrm{CO}_{2}$ and $\mathrm{H}_{2} \mathrm{O}$ [6] compared to conventional oxidants like $\mathrm{Cl}_{2}, \mathrm{ClO}_{2}$ or $\mathrm{O}_{3}$. These radicals are able to mineralize, partially or totally, most phenolic compounds. The AOP includes oxidation processes in the following:

- Homogeneous phase: $\mathrm{Fe}^{2+}\left(\mathrm{Fe}^{3+}\right) / \mathrm{H}_{2} \mathrm{O}_{2}, \mathrm{O}_{3} / \mathrm{OH}^{-}$and $\mathrm{O}_{3} / \mathrm{H}_{2} \mathrm{O}_{2}$ [7]-[9],

- Photochemical processes: UV alone, $\mathrm{H}_{2} \mathrm{O}_{2} / \mathrm{UV}, \mathrm{H}_{2} \mathrm{O}_{2} / \mathrm{Fe}^{2+}\left(\mathrm{Fe}^{3+}\right) / \mathrm{UV}$, photo-Fenton, $\mathrm{TiO}_{2} / \mathrm{UV}, \mathrm{O}_{3} / \mathrm{UV}$ [10][14],

- Direct electrochemical processes [15] [16],

- Indirect electrochemical processes [17]-[20].

Concerning the Fenton reagent $\left(\mathrm{Fe}^{2+}\left(\mathrm{Fe}^{3+}\right) / \mathrm{H}_{2} \mathrm{O}_{2}\right)$, applications are limited and they are destined specifically for industrial waste water treatment and contaminated soils depollution. The main limitations of this system include the need to operate at acidic $\mathrm{pH}$ ( $\mathrm{pH}$ approximately 3 ), the need to use large quantities of chemical reagents and the formation of ferric hydroxide [21].

By using iron supported on clays, through different procedures such as impregnation, intercalation or insertion, in the catalytic oxidation, the effectiveness of this system is significantly increased and the doses of reagents are reduced [1] [22]. This study has several objectives. Initially, this study aims to improve the degradation of three phenolic compounds, namely, hydroquinone, resorcinol and catechol using Fenton-type catalysts. This study also aims to optimize the degradation operating conditions of the response surface methodology (RSM) and to study the degradation kinetics by three types of catalyst (pillared montmorillonite, intercalated montmorillonite and impregnated kaolinite). Finally the study investigates the catalytic performance of solid catalysts by characterizing them with different techniques.

\section{Experimental}

\subsection{Materials and Instrumentation}

Two commercial clay products, montmorillonite K10 and kaolinite powder, were provided by Aldrich and Parachimic, respectively. Iron (III) solution was prepared by dissolving iron hydrochloric hexahydrate $\left(\mathrm{FeCl}_{3}\right.$, $6 \mathrm{H}_{2} \mathrm{O}$; 99\%; Merck) in purified water and for the catalytic test hydrogen peroxide solution ( $>30 \mathrm{wt} \%$, CHEMIPHARMA) was used.

The phenolic compounds were analysed by a standard HPLC instrument Younglin Acme 9000 (Eclipse column type C-18 $5 \mu \mathrm{m} 4.6 \times 250 \mathrm{~mm}$, wavelength: $254 \mathrm{~nm}$, at an injection volume of $20 \mu \mathrm{L}$, mobile phase: methanol-water: 60/40). XRD (X'PERT Pro Philps Analytical diffractometer), surface area analysis by volumetric adsorption of nitrogen (ASAP 2000 Micromeritics), and atomic absorption spectroscopy (Novo 400 Analytikjena) were performed to characterize the resultant powders.

\subsection{Catalyst Preparation}

We used two types of clay to prepare the catalysts: a swelling (montmorillonite) and a non-swelling clay (kaolinite) which were prepared according to protocols I and II (Figure 1 and Figure 2) corresponding to the intercalation of montmorillonite, its bridging and the impregnation of kaolinite.

\subsection{Catalytic Conditions}

The catalytic test is done by preparing phenolic compounds solutions ([phenolic compound] $=50 \mathrm{~mol} \cdot \mathrm{L}^{-1}$ ) 


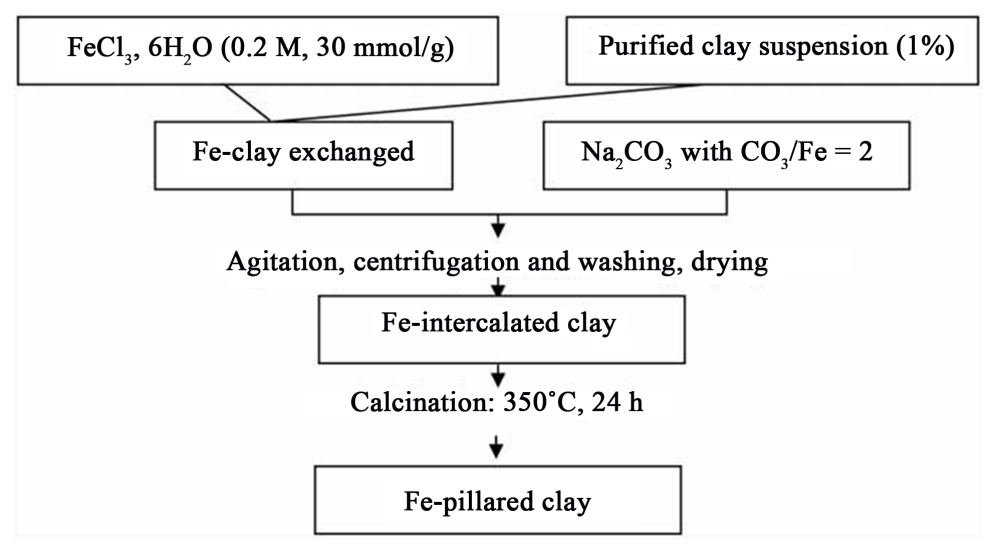

Figure 1. Preparation protocol of Fe-modified montmorillonite.

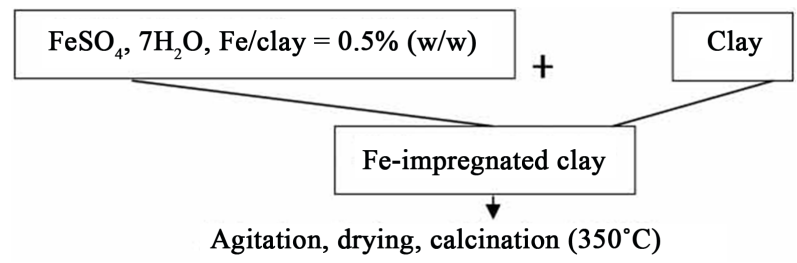

Figure 2. Preparation protocol of Fe-impregnated kaolinite.

changing the $\mathrm{pH}$ values (the $\mathrm{pH}$ were adjusted with $\mathrm{NaOH}$ or $\mathrm{HCl}$ ) and adding $\mathrm{Fe}$-powder $(0.3 \mathrm{~g})$ to the different prepared solutions using magnetic stirring to maintain a uniform suspension.

After 10 min, varying concentrations of $\mathrm{H}_{2} \mathrm{O}_{2}$ were added into the reactor and time logged.

\subsection{Investigation of Iron Release Conditions}

After the three phenolic compounds degradation test ([phenolic compound] $=50 \mathrm{~mol} \cdot \mathrm{L}^{-1}$, ambient temperature and pressure, $\mathrm{pH}=6$, catalyst mass $=0.3 \mathrm{~g}, 2 \mathrm{~mL}$ of $\left[\mathrm{H}_{2} \mathrm{O}_{2}\right]=0.26 \mathrm{M}$, solution volume $=200 \mathrm{~mL}$ ), the solution was recovered and analyzed by atomic absorption to determine the amount of iron leached from the catalysts.

\section{Result and Discussion}

\subsection{Optimization of Degradation of Phenolic Compounds by RSM}

The general practice for optimizing the operating conditions for this process consists of varying one parameter and keeping the other ones constant. The major disadvantage of this single variable optimization is the disregard of interactive effects between the variables. In order to overcome this problem, optimization studies have been carried out using RSM. The theory behind RSM has been reviewed [23] [24].

This technique is an integration of experimental strategies, mathematical methods and statistical inference to determine the optimal level giving the most interesting response. RSM reduces the number of experimental trials needed to evaluate multiple parameters and their interactions and is therefore less laborious and time consuming than other approaches. RSM has been widely applied for optimizing processes in different domains such as the chemical process, geotechnical engineering and animal science research [25]-[27]. The phenolic compounds degradation is governed by several physicochemical factors. The selected factors and their corresponding ranges can be found in Hamzaoui, Jamoussi, M’nif and Missaoui Ines [28] [29].

\subsubsection{Central Composite Design}

The applied optimization approach is based on a central composite design and RSM, this method is one of the most important experimental designs used in process optimization studies [30]. In order to describe the nature of the response surface in the optimum region, a central composite design with five coded levels was performed $(-1.68,-1,0,1,1.68)$ and three factors (t: time (min), C: concentration of $\mathrm{H}_{2} \mathrm{O}_{2}\left(\mathrm{~mol} \cdot \mathrm{L}^{-1}\right)$ and $\left.\mathrm{pH}\right)$ ) were selected 
and processed simultaneously through the central composite design.

In general, central composite designs need a total of $\left(2^{k}+2 k+N_{0}\right)$ runs where $k$ is the number of studied factors, $2^{\mathrm{k}}$ are the points from the factorial design, $2 \mathrm{k}$ the face-center points and $\mathrm{N}_{0}$ the number of experiments carried out at the center (Figure 3). As usual, the experiments were carried out in random order to minimize the effect of systematic errors.

The parameter levels and coded values are given in Table 1. Fifteen experiments were performed corresponding to the three variables central composite design (Table 2). An example of the graphical representations of the distribution of these experimental points is given in Figure 4 [30]. The measured response was defined as degradation rate in $\%$.

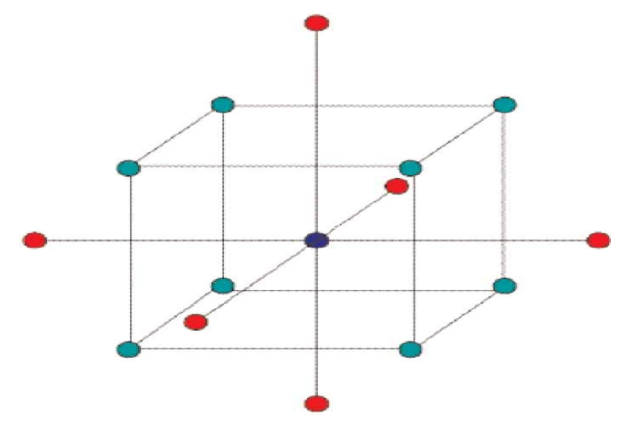

Figure 3. Spatial representation of a complete centred composite design with three factors.

Table 1. Parameter levels and coded values used in the experimental design.

\begin{tabular}{ccccccc}
\hline Parameters & Code & $+\alpha=+1.68$ & +1 & 0 & -1 & $-\alpha=-1.68$ \\
\hline Time (min) & $\mathrm{X}_{1}$ & 12.8 & 40 & 80 & 120 & 147 \\
Concentration of $\mathrm{H}_{2} \mathrm{O}_{2}\left(\mathrm{~mol} \cdot \mathrm{L}^{-1}\right)$ & $\mathrm{X}_{2}$ & 0 & 0.02 & 0.11 & 0.2 & 0.26 \\
$\mathrm{pH}$ & $\mathrm{X}_{3}$ & 0.64 & 2 & 4 & 6 & 7.36 \\
\hline
\end{tabular}

Table 2. Experimental design and response value.

\begin{tabular}{ccccccc}
\hline $\begin{array}{c}\text { Experimental } \\
\text { number }\end{array}$ & Time (min) & Concentration of $\mathrm{H}_{2} \mathrm{O}_{2}\left(\mathrm{~mol} \cdot \mathrm{L}^{-1}\right)$ & $\mathrm{pH}$ & \multicolumn{3}{c}{ Degradation rate (\%) of } \\
\cline { 5 - 7 } 1 & 120 & 0.2 & 6 & 85.66 & 0.86 & 3.92 \\
2 & 40 & 0.2 & 6 & 86.73 & 4.16 & 28.48 \\
3 & 120 & 0.02 & 6 & 79.50 & 0 & 84.08 \\
4 & 40 & 0.02 & 6 & 100.00 & 0 & 86.35 \\
5 & 120 & 0.2 & 2 & 60.31 & 0 & 18.10 \\
6 & 40 & 0.2 & 2 & 77.21 & 50.12 & 15.40 \\
7 & 120 & 0.02 & 2 & 57.74 & 39.89 & 3.62 \\
8 & 40 & 0.02 & 2 & 100.00 & 60.43 & 53.83 \\
9 & 80 & 0.11 & 4 & 58.10 & 33.96 & 48.55 \\
10 & 147 & 0.11 & 4 & 51.10 & 25.81 & 48.51 \\
11 & 12.8 & 0.11 & 4 & 53.57 & 33.73 & 48.63 \\
12 & 80 & 0.26 & 4 & 67.82 & 0 & 10.36 \\
13 & 80 & 0 & 4 & 60.20 & 69.20 & 67.82 \\
14 & 80 & 0.11 & 0.64 & 60.82 & 44.30 & 64.71 \\
\hline
\end{tabular}




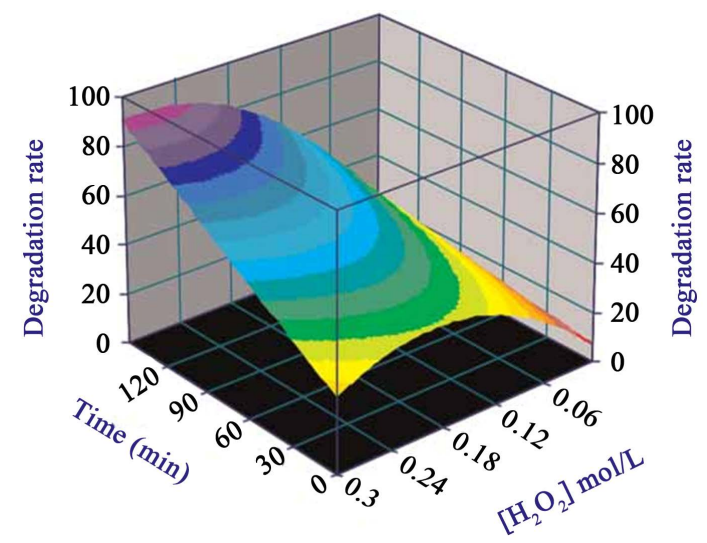

Figure 4. Three-dimensional plots for catechol degradation as a function of $\left[\mathrm{H}_{2} \mathrm{O}_{2}\right]$ and time, $\mathrm{pH}=4$.

\subsubsection{Determination of Optimal Conditions}

The quadratic response surface for the three factors involved generates a four-dimensional response surface, which can be illustrated in a three-dimensional (3D) response surface. For this, we used the software MAPLE 9.5. The surfaces were obtained by varying an experimental factor each time while keeping the third constant at its central value.

The visualization of these surfaces allows studying of the influence of each parameter and determining the optimal operating conditions to degrade the phenolic compounds, the subject of this study. An example of a graphical representation of the experimental points distribution of catechol degradation as a function of $\left[\mathrm{H}_{2} \mathrm{O}_{2}\right]$ and time at $\mathrm{Ph}=4$ is given in Figure 4. The measured response was defined as the degradation of phenolic compound in \%.

\subsection{Characterization of Fe-Modified Clays}

\subsubsection{Textural Characterization}

Measurement of specific surface $S_{B E T}$ (Brunauer, Emmett and Teller method): We noted that the natural or modified montmorillonite presents a surface with high specificity compared to that of the kaolinite (Table 3).

This can be explained by the fact that the montmorillonite is a swelling clay and its surface is formed by the internal basal surface, the external basal surface, and the external lateral surface, in addition to the surface of the pillars. This is unlike the non-swelling kaolinite which is characterized only by an external basal surface and an external lateral surface as shown in Figure 5 [31].

We also found that the $\mathrm{S}_{\mathrm{BET}}$ of intercalated montmorillonite doubled from 142 to $327 \mathrm{~m}^{2} / \mathrm{g}$ compared to that of natural montmorillonite which is probably due to the intercalation of iron polycations between the clay layers. As for the $S_{\mathrm{BET}}$ of pillared montmorillonite, we observed that it is less than the intercalated one. These results corroborate those obtained by Baccar, Batis and Ghorbel [32] who attributed this decrease to the formation of pillars of iron oxides after calcination.

\subsubsection{Structural Characterization}

Chemical analysis: Table 4 shows that the impregnated kaolinite contains a small amount of iron because the iron is impregnated on a low specific surface, in contrast to montmorillonite in which the iron can be set between its layers. In addition, the high quantity of iron in the two modified montmorillonites revealed that both clays were intercalated by iron ions. The mass percentage of iron $(42.41 \% \mathrm{w} / \mathrm{w})$ in pillared montmorillonite is higher than in the intercalated montmorillonite $(33.7 \% \mathrm{w} / \mathrm{w})$. This is probably due to the loss of water by intercalated montmorillonite therefore the mass percentage of iron increases relative to the total mass of the calcined clay.

$X$-ray diffraction: Figure 6 shows the XRD patterns of the Fe-modified montmorillonite.

The X-ray diffractogram of intercalated montmorillonite presents the 001 ray (peaks due to regular stacking of montmorillonite layers) whose position corresponds to a distance between the layers of d001 $=10.24 \AA$. This ray on the diffractogram of pillared montmorillonite moves to d001 $=9.12 \AA$. 


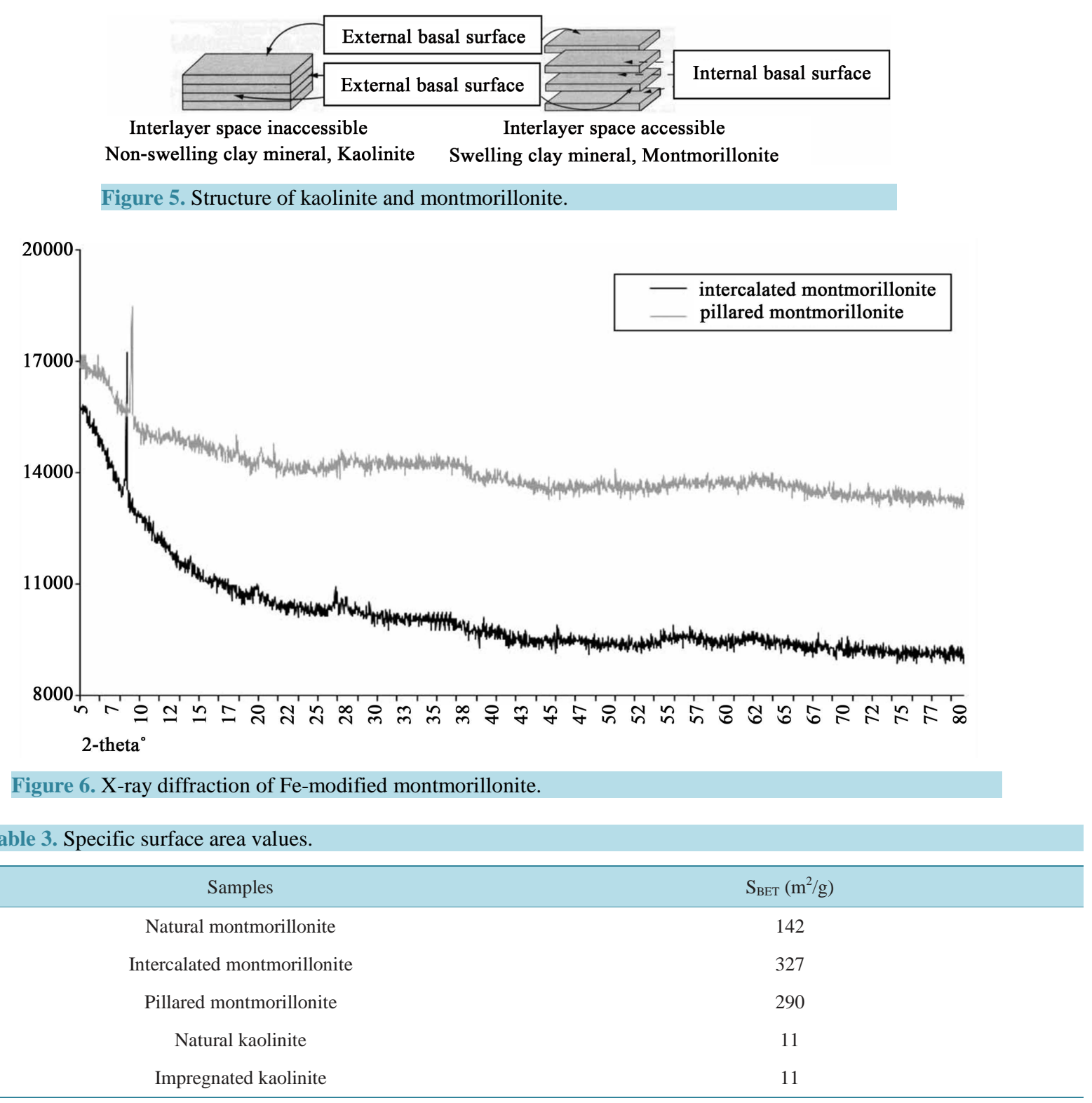

Table 4. Values of iron amount in clay.

\begin{tabular}{cccc}
\hline Samples & Intercalated montmorillonite & Pillared montmorillonite & Impregnated kaolinite \\
\hline Iron amount $(\% \mathrm{w} / \mathrm{w})$ & 33.7 & 42.41 & 7.99 \\
\hline
\end{tabular}

This slight decrease from 10.24 to $9.12 \AA$ in the distance between the layers in the two clays reveals that the large polycations of iron inserted between the layers after calcination become pillars of iron oxides which are less bulky.

The X-ray diffractogram of the Fe-impregnated kaolinite (Figure 7) shows the rays of iron oxide that confirms their setting on kaolinite.

\subsubsection{Investigation of Iron Release}

We notice in Table 5 that the presence of leached iron in the solution induces the degradation of phenolic compounds according to homogeneous catalysis in addition to the heterogeneous catalysis. In fact the first catalysis is the result of the leached iron in the solution and the second one is caused by iron supported by clays. 


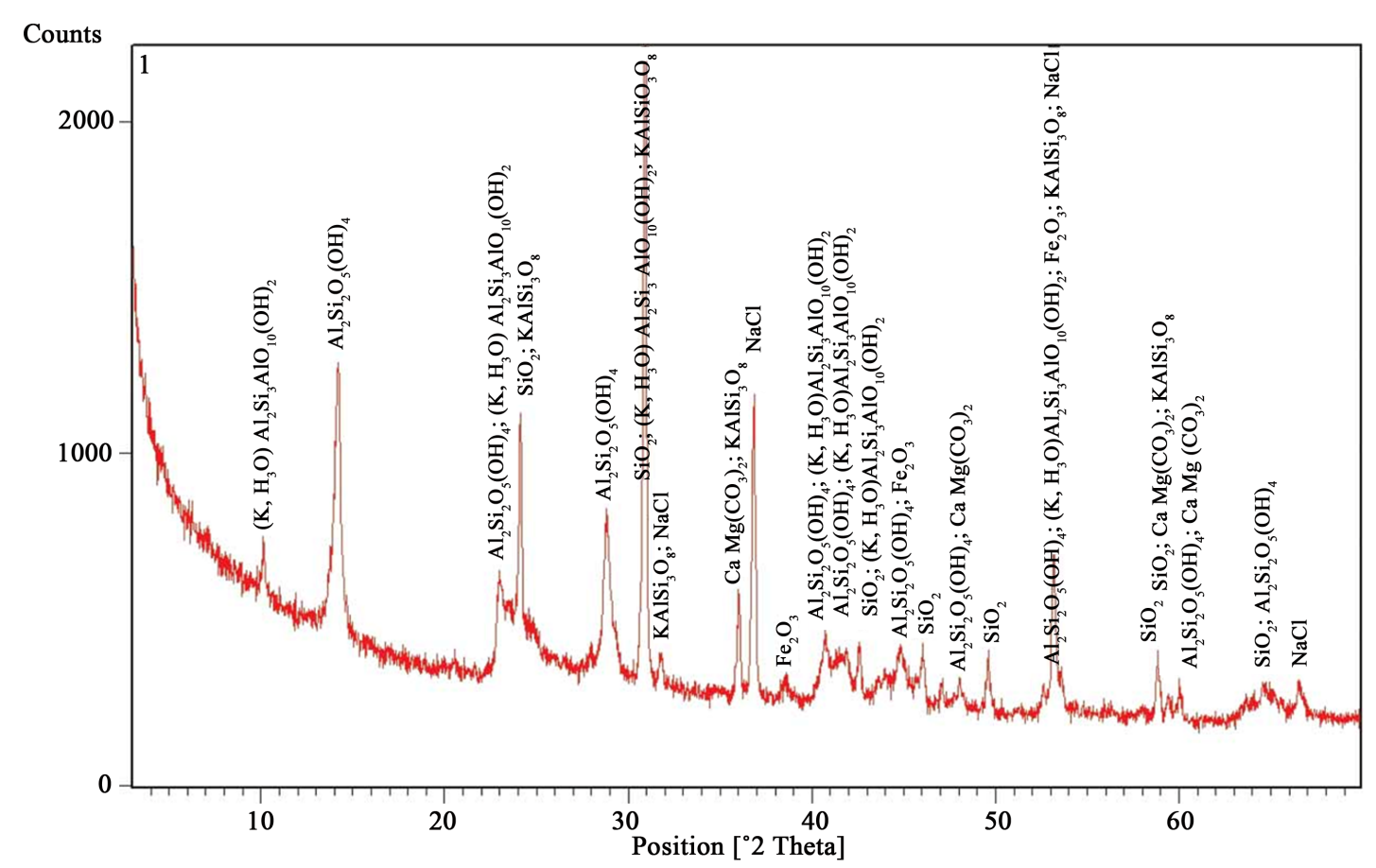

Figure 7. X-ray diffraction of Fe-impregnated kaolinite.

Table 5. Iron amount leached.

\begin{tabular}{cccc}
\hline Samples & Intercalated montmorillonite & Pillared montmorillonite & Impregnated kaolinite \\
\hline Iron amount leached $\left(\mathrm{mol} \cdot \mathrm{L}^{-1}\right)$ & 0.415 & 1.619 & 58 \\
\hline
\end{tabular}

We also note that the kaolinite leached a significant amount of iron $\left(58 \mathrm{mg} \cdot \mathrm{L}^{-1}\right)$. Thus, it does not yet support iron ions on its compact surface and these are not trapped between its layers. Both prepared montmorillonites released lesser amounts of iron ( 1.69 and $\left.0.415 \mathrm{mg} \cdot \mathrm{L}^{-1}\right)$ because iron ions were trapped between layers of clay. In summary, the catalysts prepared by swelling clays such as montmorillonite are more efficient than those prepared with compact structure clays.

\subsection{Kinetics of Catalytic Degradation of Phenolic Compounds}

The apparent degradation rate was determined by plotting the curve of $\ln \left([\mathrm{C}]_{0} /[\mathrm{C}]\right)$, as a function of time. $[\mathrm{C}]_{0}$ is the phenolic compound concentration at $\mathrm{t}=0$ and the $[\mathrm{C}]$ is the phenolic compound concentration at $\mathrm{t}$. The equation was found to be first order.

The phenolic compounds degradation rate constants histogram (Figure 8) reveals that hydroquinone is the most degraded compound in the least amount of time and that modified montmorillonite is more efficient to degrade the phenolic compound than impregnated kaolinite; this is probably due to its interlayer structure which maintains iron ions between layers and to its high surface specificity compared to kaolinite.

\subsection{Determination of Optimal Degradation Conditions}

We traced the response surfaces of each compound by repeatedly varying two experimental factors and keeping the third constant at its central value (the $\mathrm{pH}$ was chosen at 4, the central value of time was 80 min and the $\mathrm{H}_{2} \mathrm{O}_{2}$ concentration was $0.11 \mathrm{M}$ ). For catechol (Figure 4), the optimal degradation conditions at $\mathrm{pH} 4$ are obtained after 120 min with a concentration of $\mathrm{H}_{2} \mathrm{O}_{2}$ equal to $0.3 \mathrm{M}$. If we fix the $\mathrm{H}_{2} \mathrm{O}_{2}$ concentration at $0.11 \mathrm{M}$, the optimal conditions are obtained after $120 \mathrm{~min}$ and at $\mathrm{pH}$ less than 1.6. When the time of reaction is equal to $80 \mathrm{~min}$, the optimal degradation is obtained at $\mathrm{pH}$ less than 3.2 and at a $\mathrm{H}_{2} \mathrm{O}_{2}$ concentration more than $0.12 \mathrm{M}$. 


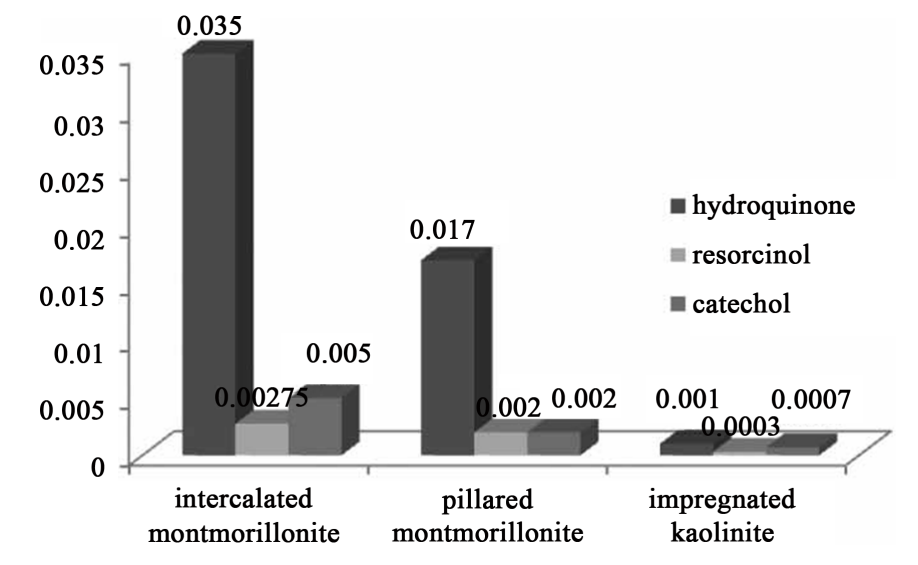

Figure 8. Histogram of rate constants of phenolic compounds degradation.

\section{Conclusions}

This study clearly shows the following:

-The use of the RSM allows the visualization of degradation response surfaces of each compound, the study of the influence of each parameter $\left(\mathrm{pH}, \mathrm{H}_{2} \mathrm{O}_{2}\right.$ concentration and time reaction) and the determination of the optimal operating conditions to degrade the selected phenolic compounds.

-The results obtained from the catalytic tests and analysis performed by different techniques show that the modified montmorillonites have very distinct catalytic, structural and textural properties; they are more effective for the catalytic phenolic compound degradation, they present the highest surface specificity and they may support iron ions.

-The kinetic degradation of three phenolic compounds supports the fact that hydroquinone is the most degraded compound in the least amount of time.

-The control of the release of iron ions by the catalysts performed by atomic absorption spectroscopy shows that the rate of the catalyst iron ions release in the reaction when the Fe-modified montmorillonites are used is lower than when Fe-modified kaolinite is used.

\section{References}

[1] Liotta, L.F., Gruttadauria, M., Carlo, G.D., Perrini, G. and Librando, V. (2009) Heterogeneous Catalytic Degradation of Phenolic Substrates: Catalysts Activity. Journal of Hazardous Materiels, 162, 588-606. http://dx.doi.org/10.1016/j.jhazmat.2008.05.115

[2] Hammami, S., Oturan, N., Bellakhal, N., Dachraoui, M. and Oturan, M.A. (2007) Oxidative Degradation of Direct Orange 61 by Electro-Fenton Process Using a Carbon Felt Electrode: Application of the Experimental Design Methodology. Journal of Electroanalytical Chemistry, 610, 75-84. http://dx.doi.org/10.1016/j.jelechem.2007.07.004

[3] Kesraoui, A., Oturan, N., Bellakhal, N., Dachraoui, M. and Oturan, M.A. (2008) Experimental Design Methodology Applied to Electro-Fenton Treatment for Degradation of Herbicide Chlortoluron. Applied Catalysis B: Environmental, 78, 334-341. http://dx.doi.org/10.1016/j.apcatb.2007.09.032

[4] Lynch, B.S., Delzell, E.S. and Bechtel, D.H. (2002) Toxicology Review and Risk Assessment of Resorcinol: Thyroid Effects. Regulatory Toxicology and Pharmacology, 36, 198-210. http://dx.doi.org/10.1006/rtph.2002.1585

[5] Iurascu, B., Siminiceanu, I., Vione, D., Vicente, M.A. and Gil, A. (2009) Phenol Degradation in Water through a Heterogeneous Photo-Fenton Process Catalyzed by Fe-Treated Laponite. Water Research, 43, 1313-1322. http://dx.doi.org/10.1016/j.watres.2008.12.032

[6] Kesraoui, A., Oturan, M.A., Oturan, N., Bellakhal, N. and Dachraoui, M. (2010) Treatment of an Aqueous Pesticides Mixture Solution by Direct and Indirect Electrochemical Advanced Oxidation Processes. International Journal of Environmental Analytical Chemistry, 90, 1029-1397.

[7] Sanz, J., Lombrana, J.I., Deluis, A.M., Ortueta, M. and Varona, F. (2003) Microwave and Fenton’s Reagent Oxidation of Wastewater. Environmental Chemistry Letters, 1, 45-50. http://dx.doi.org/10.1007/s10311-002-0007-2

[8] Chamarro, E., Marco, A. and Esplugas, S. (2001) Use of Fenton Reagent to Improve Organic Chemical Biodegradability. Water Research, 35, 1047-1050. http://dx.doi.org/10.1016/S0043-1354(00)00342-0 
[9] Hoigné, J. (1998) Chemistry of Aqueous Ozone and Transformation of Pollutants by Ozonation and Advanced Oxidation Processes. The Handbook of Environmental Chemistry, Quality and Treatment of Drinking Water II (J. Hrubec, Ed.), Springer, Berlin, 5, 83-141.

[10] Aleboyeh, A., Moussa, Y. and Aleboyeh, H. (2005) The Effect of Operational Parameters on UV/ $\mathrm{H}_{2} \mathrm{O}_{2}$ Decolourisation of Acid Blue 74. Dyes and Pigments, 66, 129-134. http://dx.doi.org/10.1016/j.dyepig.2004.09.008

[11] Daneshvar, N., Rabbani, M., Modirshahla, N. and Behnajady, M.A. (2005) Photooxidative Degradation of Acid Red 27 in a Tubular Continuous-Flow Photoreactor: Influence of Operational Parameters and Mineralization Products. Journal of Hazardous Materials, 118, 155-160. http://dx.doi.org/10.1016/j.jhazmat.2004.10.007

[12] Liu, P., Li, C., Zhao, Z., Lu, G., Cui, H. and Zhang, W. (2013) Induced Effects of Advanced Oxidation Processes. Scientific Reports, 4, 1-4.

[13] Herrmann, J.M., Guillard, C., Arguello, M., Agüera, A., Tejedor, A., Piedra, L. and Alba, A.F. (1999) Photocatalytic Degradation of Pesticide Pirimiphos-Methyl: Determination of the Reaction Pathway and Identification of Intermediate Products by Various Analytical Methods. Catalysis Today, 54, 353-367. http://dx.doi.org/10.1016/S0920-5861(99)00196-0

[14] Lhomme, L., Brosillon, S., Wolbert, D. and Dussaud, J. (2005) Photocatalytic Degradation of a Phenylurea, Chlortoluron, in Water Using an Industrial Titanium Dioxide Coated Media. Applied Catalysis B: Environmental, 61, $227-235$. http://dx.doi.org/10.1016/j.apcatb.2005.06.002

[15] Comninellis, C. and Pulgarin, C. (1991) Anodic Oxidation of Phenol for Waste Water Treatment. Journal of Applied Electrochemistry, 21, 703-708. http://dx.doi.org/10.1007/BF01034049

[16] Boye, B., Dieng, M.M. and Brillas, E. (2002) Degradation of Herbicide 4-Chlorophenoxyacetic Acid by Advanced Electrochemical Oxidation Methods. Environmental Science and Technology, 36, 3030-3035. http://dx.doi.org/10.1021/es0103391

[17] Hanna, K., Chiron, S. and Oturan, M. (2005) Coupling Enhanced Water Solubilization with Cyclodextrin to Indirect Electrochemical Treatment for Pentachlorophenol Contaminated Soil Remediation. Water Research, 39, 2763-2773. http://dx.doi.org/10.1016/j.watres.2005.04.057

[18] Bellakhal, N., Dachraoui, M., Oturan, N. and Oturan, M.A. (2006) Degradation of Tartrazine in Water by ElectroFenton Process. Journal de la société chimique de Tunisie, 8, 223-228.

[19] Hammami, S., Bellakhal, N., Oturan, N., Oturan, M.A. and Dachraoui, M. (2008) Degradation of Acid Orange 7 by Electrochemically Generated $\mathrm{OH}^{-}$Radicals in Acidic Aqueous Medium Using a Boron-Doped Diamond or Platinum Anode: A Mechanistic Study. Chemosphere, 73, 678-684. http://dx.doi.org/10.1016/j.chemosphere.2008.07.010

[20] Vinodgopal, K. and Peller, J. (2013) Hydroxyl Radical-Mediated Advanced Oxidation Processes for Textile Dyes: A Comparison of the Radiolytic and Sonolytic Degradation of the Monoazo Dye Acid Orange 7. Journal of Agricultural and Food Chemistry, 29, 307-316.

[21] Nam, K., Rodriguez, W. and Kukor, J.J. (2001) Enhanced Degradation of Polycyclic Aromatic Hydrocarbons by Biodegradation Combined with a Modified Fenton Reaction. Chemosphere, 45, 11-20. http://dx.doi.org/10.1016/S0045-6535(01)00051-0

[22] Luo, M., Bowden, D. and Brimblecombe, P. (2009) Catalytic Property of Fe-Al Pillared Clay for Fenton Oxidation of Phenol by $\mathrm{H}_{2} \mathrm{O}_{2}$. Applied Catalysis B: Environmental, 85, 201-206. http://dx.doi.org/10.1016/j.apcatb.2008.07.013

[23] Gonçalves, D.B., Teixeira, J.A., Bazzolli, D.M., Queiroz, M.V. and Fernandes, E. (2012) Use of Response Surface Methodology to Optimize Production of Pectinases by Recombinant Penicillium griseoroseum T20. Biocatalysis and Agricultural Biotechnology, 1, 140-146. http://dx.doi.org/10.1016/j.bcab.2011.09.002

[24] Khataee, A.R., Zarei, M. and Moradkhannejhad, L. (2010) Application of Response Surface Methodology for Optimization of Azo Dye Removal by Oxalate Catalyzed Photoelectro-Fenton Process Using Carbon Nanotube-PTFE Cathode. Desalination, 258, 112-119. http://dx.doi.org/10.1016/j.desal.2010.03.028

[25] Ravikumar, K., Ramalingam, S., Krishnan, S. and Balu, K. (2006) Application of Response Surface Methodology to Optimize the Process Variables for Reactive Red and Acid Brown Dye Removal Using a Novel Adsorbent. Dyes and Pigments, 70, 18-26. http://dx.doi.org/10.1016/j.dyepig.2005.02.004

[26] Sayon, E. (2006) Ultrasound-Assisted Preparation of Active Carbon from Alkaline Impregnated Hazelnut Shell: An Optimization Study on Removal of $\mathrm{Cu}^{2+}$ from Aqueous Solution. Chemical Engineering Journal, 115, 213-218. http://dx.doi.org/10.1016/j.cej.2005.09.024

[27] Zhao, D., Ding, C., Wu, C. and Xu, X. (2012) Kinetics of Ultrasound-Enhanced Oxidation of p-Nitrophenol by Fenton's Reagent. Energy Procedia: 2012 International Conference on Future Energy, Environment, and Materials, 16, 146-150.

[28] Hamzaoui, A., Jamoussi, B. and M’nif, A. (2008) Lithium Recovery from Highly Concentrated Solutions: Response Surface Methodology (RSM) Process Parameters Optimization. Hydrometallurgy, 90, 1-7. 
http://dx.doi.org/10.1016/j.hydromet.2007.09.005

[29] Missaoui, I., Sayedi, L., Jamoussi, B. and Ben Hassine, B. (2009) Response Surface Optimization for Determination of Volatile Organic Compounds in Water Samples by Headspace-Gas Chromatography-Mass Spectrometry Method. Journal of Chromatographic Science, 47, 257-262. http://dx.doi.org/10.1093/chromsci/47.4.257

[30] Myer, R. and Montgomery, D.C. (2002) Response Surface Methodology. John Wiley and Sons Inc., New York.

[31] Luster, J., Kalbitz, K., Lennartz, B. and Rinklebe, J. (2014) Properties, Processes and Ecological Functions of Floodplain, Peatland, and Paddy Soils. Geoderma, 228-229, 1-4. http://dx.doi.org/10.1016/j.geoderma.2014.04.010

[32] Baccar, A., Batis, N. and Ghorbel, A. (2005) Facts of Parameters and Protocol Preparation on Structural and Textural Properties of Iron (III) Intercalated Clay. Journal de la société chimique de Tunisie, 7, 173-186. 